\title{
ENFERMAGEM: IDEALISMO X REALISMO \\ PERSPECTIVAS DE FORMANDOS DO CURSO DE GRADUAÇÃO DE ENFERMAGEM SOBRE A PROFISSÃO DE ENFERMAGEM
}

\author{
NURSING: IDEALISM X REALISM. PERSPECTIVES ABOUT NURSING \\ PROFESSION FROM NURSING STUDENTS ENROLLED IN THEIR LAST \\ SEMESTER OF THE UNDER-GRADUATE PROGRAM OF A NURSING SCHOOL
}

\author{
ENFERMERÍA: IDEALISMO X REALISMO. \\ PERSPECTIVAS DE ESTUDIANTES DE ENFERMERÍA EN FINAL DE CURSO \\ SOBRE LA PROFESIÓN DE ENFERMERÍA
}

\author{
Taka Oguisso*** \\ Lucia Kanako Seki** \\ Giane Leandro de Araujo* \\ Claudia Akemi Shibuya* \\ Cristiane Speciale* \\ Monica Martins Trovó *
}

\begin{abstract}
Oguisso T, Seki LK, Araujo GL, Shibuya CA, Speciale C, Trovó MM. Enfermagem: idealismo x realismo, Perspectivas de formandos do curso de graduação de enfermagem sobre a profissão de enfermagem. Rev Esc Enferm USP 2001; 35(3):271-81.

\section{RESUMO}

Estudo exploratório descritivo com os objetivos de: identificar os sentimentos dos formandos de uma Escola de Enfermagem em relação ao curso de graduação e sua percepção quanto à profissão de enfermagem. Após quatro anos de curso, 57,4\% dos estudantes percebiam a enfermagem de maneira positiva, como profissão do futuro, valorizada, reconhecida, compensadora, mesmo que com algumas ressalvas, Entretanto, 25\% dos formandos ainda a percebiam como profissão mecânica, sacrificada, braçal, com visão científica limitada e com um abismo entre teoria e prática e por isso mesmo pouco reconhecida pela sociedade, Mantidas as tendências atuais, a valorização do enfermeiro pela sociedade brasileira nas próximas décadas seria muito maior, conforme $61 \%$ dos respondentes,
\end{abstract}

PALAVRAS -CHAVE: Enfermagem, estudantes de enfermagem. Sentimentos,

\begin{abstract}
Exploratory and descriptive study with the following objectives: to identify the nursing students' feelings related to the undergraduate course and their perception towards the nursing profession, After the four-year course, 57,4\% of students perceived nursing in a positive way as a profession for the future, valued, recognised, compensating even with some limitations, However, 25\% of students still perceived nursing as a mechanical, manual and sacrificed profession, with a limited scientific vision and with a gap between theory and practice and as a consequence a lower recognition by the society. If current trends are maintained, the nurse's value would be much greater in the next decades within the Brazilian society according to $61 \%$ of respondents.
\end{abstract}

KEYWORDS: Nursing. Student's nursing, Emotions,

\section{RESUMEN}

Estúdio exploratório y descriptivo con objectivos de: identificar los sentimientos de los estudiantes en final de curso de una Escuela de Enfermería con relación al curso y su percepción hacia la profesión de enfermería, Después de quatro años de curso, 57,4\% de los estudiantes percibian la enfermeria de manera positiva, como profesión del futuro, valorizada, reconocida, compensadora, mismo con algunas reservas. Mientras tanto 25\% percibian la enfermería como pro fesión brazal, con visión científica limitada y con un abismo entre la teoria y la práctica, Por esto mismo poco reconocida por la sociedad. Mantenidas las tendencias actuales, la valorización del enfermero por la sociedad brasileña en las próximas décadas seria mucho mayor, segun $61 \%$ de los respondientes.

PALABRAS-CLAVE: Enfermería. Estudiantes de enfermería, Emociones.

\footnotetext{
* $\quad$ Alunas do $4^{\circ}$ ano do Curso de Graduação em Enfermagem da EEUSP.

** Enfermeira. Formada pela EEUSP.

*** Enfermeira e advogada. Professora Titular do Departamento de Orientação Profissional da EEUSP.
} 


\section{INTRODUÇÃO}

O interesse por este estudo surgiu em decorrência de um trabalho realizado, em março de 1999, com alunos do $1^{\circ}$ ano de graduação, da Escola de Enfermagem da Universidade de São Paulo (EEUSP) durante as aulas de um dos módulos da disciplina ENO-101 Introdução à Enfermagem, Essa disciplina, de seis créditos e 90 horas-aula, coordenada pelo Departamento de Orientação Profissional, é obrigatória e os temas relacionados com a História da Enfermagem, assim como seus aspectos éticos e legais, é ministrada pela autora docente deste trabalho, Como parte das atividades discentes, logo no início da disciplina, os alunos deveriam entrevistar três pessoas, entre familiares, amigos, conhecidos e desconhecidos, a respeito da percepção dessas pessoas sobre a profissão de enfermagem e as qualidades que um enfermeiro deveria ter. Os dados colhidos pelos alunos, nas entrevistas, foram reunidos em um quadro em ordem decrescente de freqüência das respostas obtidas, e os resultados discutidos com todos. As respostas encontradas estavam carregadas de preconceitos sociais, estigmas e opiniões negativas. Munidos desses dados de uma realidade recémdescoberta, além da informação sobre a evolução histórica da enfermagem no Brasil e no mundo, os alunos deveriam projetar como a profissão poderia evoluir nas décadas seguintes e descrevê-la num outro exercício na forma de uma carta-testamento, Imaginando-se estar no ano 2050, quando a maioria desses alunos do $1^{\circ}$ ano estaria próxima ou teria atingido os 70 anos de idade, deveriam escrever uma carta-testamento a um descendente. Nessa carta deveriam descrever os progressos que a Enfermagem teria alcançado desde a formatura no ano 2003.

Quatro alunas, ingressantes em 1999, manifestaram o desejo de fazer alguma pesquisa com a docente. Entre as vertentes discutidas, foi sugerido estudar a opinião de formandos sobre como eles viam a profissão que estavam prestes a abraçar e compará-la com a ótica dos ingressantes, Embora existissem artigos e teses sobre perfil de estudantes de enfermagem, um novo estudo poderia explorar outros aspectos do problema, Foi considerado que a presença de um colega formando no grupo seria de grande valia, por sua maior vivência dentro do ambiente da Escola, e também para ajudar na identificação dos formandos ou na distribuição dos questionários, A aluna do $4^{\circ}$ ano, bolsista do Programa Institucional de Bolsas de Iniciação Científica - PIBIC, do Conselho Nacional de Desenvolvimento Científico e Tecnológico - CNPq, num trabalho com a autora-docente foi convidada e é uma das co-autoras deste estudo,

A autorização escrita para uso das informações contidas nas cartas-testamento dos alunos do $1^{\circ}$ ano de 1999 foi dada por eles, por unanimidade, Apenas dois alunos, autores dessas cartas, não puderam ser localizados por haverem desistido do curso. Essas cartas foram excluidas do estudo, As cartastestamento foram reproduzidas e distribuidas para análise e seus conteúdos deveriam ser organizados em grupos, por semelhança de idéias, destacando-se as expressões mais originais.

Dentre as expressões mais freqüentes encontradas nas cartas-testamento constavam: que a enfermagem seria a carreira mais disputada pelos candidatos ao exame vestibular da Fuvest, profissão mais almejada, valorizada, nobre e competente do setor saúde. A maioria demonstrou otimismo com relação ao futuro da enfermagem, crendo que enfermeiros até o ano 2050 teriam sido eleitos deputados federais e até mesmo presidente da República e nomeados para exercer o cargo de ministro da saúde. Acreditavam também que já teria sido criada a Academia Brasileira de Enfermagem, a Fundação Paulista de Enfermagem, assim como o Prêmio Nobel de Enfermagem. Fizeram também abordagens muito realistas, prevendo aumento da expectativa de vida e do número de idosos, tornando ainda mais importante a formação de enfermeiros para cuidar dessa população, Outros demonstraram ufanismo, afirmando que o Brasil em 2050 teria se tornado uma potência mundial da saúde. Muitas cartas revelaram também idealismo, afirmando que o enfermeiro enxergava a alma do paciente, que ele sentia necessidade de ajudar o próximo. Muitos reconheceram que a enfermagem era uma profissão que exige atenção, paciência, coragem, dedicação, agilidade e capacidade. Uma das alunas cunhou uma expressão muito significativa de que "não existe cura sem cuidado, mas que existe cuidado sem cura", o que denota um profundo sentimento sobre a limitação humana e noção de distinção entre esses dois componentes da assistência à saúde: o cuidar e o curar, o que é notável num estudante de $1^{\circ}$ ano de graduação. Mas essa mesma aluna expressa também tristeza, dizendo que mesmo com a mudança de século e todas as transformações sociais os enfermeiros não teriam sido lembrados ou mencionados.

Estudo similar(1) de 1998 revelou que estudantes que buscavam a carreira de Enfermagem, por acaso ou como opção principal, eram alunos provenientes de famílias inseridas num contexto onde os valores, tais como status social e ganhos consideráveis, eram muitas vezes determinantes na escolha da carreira ou profissão. Porém, nem sempre os jovens escolhem a carreira apenas baseados nesses valores, mas pela vontade de "ajudar as pessoas" ou um ideal, dados esses que obtiveram grande freqüência $(70 \%)$ entre os estudantes em um trabalho realizado em 1981, por Arcuri (2). e entre as três respostas mais freqüentes obtidas no trabalho de Horta (3). Nota-se, pois, que entre os jovens prevalece o idealismo e o interesse em ajudar o próximo como fator importante na escolha de uma profissão, 
Supondo-se que alunos ingressantes são naturalmente idealistas, como os estudos acima e outros têm constatado, o interesse agora é saber se esse ideal do $1^{\circ}$ ano é mantido durante os quatro anos do curso de graduação ou se ele sofre modificações, Nesse caso, que modificações seriam essas e porquê elas ocorreriam. Será que ao deixar os bancos escolares, esses alunos estariam motivados a exercer a profissão com orgulho e entusiasmo? Que aspirações, expectativas ou preocupações teriam em relação ao próprio futuro profissional? Teriam vontade de influenciar de algum modo nos destinos da profissão escolhida? Nesse caso, como imaginariam ser possivel introduzir as melhorias pretendidas?

\section{Objetivos:}

Este estudo pretende identificar:

- os sentimentos dos ahunos formandos da Escola de Enfermagem da USE em relação ao curso de graduação de enfermagem e

\section{- $\quad$ sua percepcão quanto à profissão de enfermagem.}

Além disso, com a realização deste trabalho, estudantes novatos tiveram a oportunidade de participar num trabalho de pesquisa, desde a definição do problema, elaboração das hipóteses, dos objetivos, a construção do questionário, do projeto e do protocolo de pesquisa, a metodologia a ser seguida, a análise e interpretação de dados, o relatório assim como na formação de atitudes éticas adequadas em uma pesquisa desenvolvida junto com uma docente. Igualmente, o convivio com uma aluna veterana com suas opiniões e pontos de vista foi uma experiência importante e um valioso estímulo para iniciantes.

Apesar de não terem freqüentado ainda as disciplinas de metodologia da pesquisa, a vivência prática de todas as fases de uma situação de pesquisa poderia despertar o interesse delas para o futuro, A curiosidade de aprender mais, de compartilhar suas idéias com outras colegas igualmente interessadas em fazer algo diferente motivou individualmente as calouras a buscarem com entusiasmo essa oportunidade para um trabalho em grupo. A aluna formanda, por seu lado, disse ter-se surpreendido com o convite, pois nunca pensara em uma possibilidade de fazer esse tipo de troca de idéias com recémingressantes na EEUSP, e sentiu sua responsabilidade na posição de veterana, De um modo geral os alunos não dispõem de tempo para esse tipo de convivio com colegas de outras turmas durante o período escolar. Esta foi uma ocasião propícia para a mútua troca de idéias e experiências.

\section{Hipóteses:}

a) 0 curso de graduação da EEUSP modifica a percepção do estudante quanto à profissão de enfermagem. c) $O$ formando, às vésperas de concluir sua graduação em enfermagem, vê a profissão sem grande entusiasmo ou idealismo.

c)O desejo de ajudar o próximo, manifestado no início do curso, não persiste até o final do curso.

\section{REVISÃO DA LITERATURA}

No decorrer do processo de preparação formal para uma profissão, é comum as pessoas enfrentarem situações de dúvida quanto à escolha feita, medo de não terem feito a escolha correta, insegurança quanto ao futuro, ansiedade pelas incertezas, angústia e outros sentimentos que podem estar agravados por fatores sócio-econômicos, ou associados a problemas familiares. Esses fatores em conjunto podem desencadear reações de agressividade ou, ao contrário, de passividade e inércia, conforme autores pesquisados,

A opção pela enfermagem pelo homem enfermeiro é estudado por Vargens (4) que identificou como marcos decisórios do processo, o vestibular, a formatura e entre eles, durante a formação acadêmica, a passagem do ciclo básico para o profissionalizante, em especial a disciplina Fundamentos de Enfermagem, percebida como o primeiro contato com a realidade "real" e não apenas ideológica, O autor refere que esse é um momento crucial de decidir se continua ou não na profissão. Sua relação com a escola, no desenrolar do seu processo de formação, mostra-se repleta de atritos, decepções e conflitos, chegando o autor a definir a atuação da escola de submeter o aluno a uma "prova de fogo", caracterizando o aprendizado de "traumático".

Em sua tese sobre formação de atitudes éticoprofissionais, Nakamae (5), analisando depoimentos de alunos, refere que eles demonstravam "insegurança por falta de maturidade, medo de se expressar e receber represálias, intervenções inócuas nas sugestões de mudanças; comodismo gerando imobilismo - embora aceitem a culpa da omissão e negligência, não reivindicam e têm consciência de que nada fizeram para mudar a situação que os afeta - despolitização decorrente, em parte, da bagagem mínima de orientação éticopolítica e, de certo modo, imposição por algumas disciplinas de aceitação sem despertar o senso critico".

Jorge', professora de Enfermagem Psiquiátrica no $8^{\circ}$ semestre do curso de graduação, percebeu que eles estavam "angustiados, com movimentos demonstrativos de instabilidade emocional, através de falas e outras expressões". A autora notou que, a problemática, muitas vezes, era em âmbito familiar, outras, devido a relações entre colegas e, outras ainda, referentes ao curso ou às suas inquietações quanta à profissão que estariam exercendo dentro em pouco. 
É fato conhecido, como refere Angelo(7), que nem todas as pessoas que optam pela enfermagem o fazem por ser esta a profissão relacionada ao seu interesse ou aptidão, Essa autora encontrou em seu levantamento, que em 1990, a maioria (58\%) tinha preferência por outras carreiras, sendo que destas a preferencial era Medicina com 35\% dos alunos, Já em 1995, a maioria $(68,7 \%)$ tinha a Enfermagem como sua carreira de preferência. Com relação a outros cursos, além de representar a situação de $15 \%$ dos alunos ingressantes, apenas 10\% tinham Medicina como opção, Mas em seu levantamento, a autora notou a elevada percentagem $(11,3 \%)$ de alunos que não sabia se Enfermagem era, de fato, a carreira de sua escolha,

Barbosa (8) iniciou seu estudo sobre a percepção do aluno de enfermagem sobre o processo de sua formação acadêmica, ao observar que grande parte dos alunos tinha uma postura acrítica, passiva e pouco participativa. Analisou o discurso de 24 alunos matriculados no curso, através de entrevista semiestruturada, quando verificou que a pedagogia utilizada caracterizava-se por uma orientação rígida, autoritária e desvinculada das determinações sociais.

No estudo sobre a compreensão do ideário da enfermagem para a transformação da prática profissional, com alunas do curso de graduação em enfermagem, Padilha( ${ }^{(9)}$ obtiveram respostas indicando que a Enfermagem é percebida como uma profissão de amor ao próximo, uma forma de chegar perto de Deus, mas também como desafio e luta por uma profissão melhor.

Após uma reforma do ensino de enfermagem, Manninen ${ }^{(10)}$ realizou um estudo longitudinal de três anos, 1989-92, para examinar as percepções de estudantes de enfermagem finlandeses após 6, 18, 30 meses e ao final do curso de sete semestres. Nos primeiros quatro semestres todos os alunos seguem o mesmo curso e nos últimos três semestres os alunos são levados ao ensino especializado em enfermagem médico-cirúrgica, psiquiátrica, pediátrica, em anestesia e centro cirúrgico, saúde pública e obstetrícia. A população foi de 158 estudantes de um total de 1129 , distribuídos em 26 instituições de saúde, $\mathrm{O}$ instrumento foi um questionário e a maioria dos estudantes respondeu quatro vezes. A autora concluiu que a reforma, iniciada em 1987, ajudou estudantes a priorizar e identificar os aspectos essenciais do cuidado de enfermagem e da promoção da saúde, de forma que em nenhuma fase do estudo, o modelo médico ou centrado na doença obteve relevância.

Em seu estudo, Spíndola, Moreira (11) investigaram as motivações da opção profissional pelo estudante de enfermagem e os seus conhecimentos a respeito da profissão, Concluíram que as motivações estavam relacionadas com a aptidão pela área da saúde, influência de amigos/familiares, percepção da enfermagem como próxima às demais áreas de saúde e fértil mercado de trabalho,
Num estudo sobre o imaginário dos familiares das alunas ingressantes no curso de graduação, na escuta crítica sobre a conduta das pessoas, apoiando ou não, os filhos na sua opção profissional, Silva( ${ }^{(12)}$, concluiu que a instituição Enfermagem deveria ter um projeto pedagógico que incluísse a parceria dos familiares das alunas na construção social visível desta profissão para a sociedade,

Refere Freitas ${ }^{(13)}$ que a escolha da profissão de enfermagem é vista pelas educandas de enfermagem como dificil, repleta de ansiedades e conflitos devido à falta de conhecimento das famílias e da sociedade em geral sobre a profissão. Enfatiza que "as relações e o impacto da imagem social relacionada à profissão em nossa sociedade e em nossa cultura reforçam a baixa auto-estima das educandas e dos profissionais que desejam e buscam transformações significativas para afirmar a Enfermagem enquanto profissão do cuidado".

\section{MATERIAL E MÉTODO}

Trata-se de um estudo exploratório descritivo sobre a percepção de estudantes em final do curso de graduação sobre a profissão de enfermagem. Este método, segundo Kerlinger (14), procura determinar a incidência e a distribuição das características e opiniões de populações de pessoas, obtendo e estudando as características e opiniões de amostras pequenas e presumivelmente representativas de tais populações.

Instrumento - questionário com perguntas abertas e fechadas. O grupo optou pelo questionário, por ser mais fácil para colher os dados e analisar as características e opiniões dos formandos. Esse questionário, contendo 19 perguntas abertas e fechadas, foi preenchido pelos estudantes do $8^{\circ}$ semestre de graduação da EEUSP. Conforme foi explicitado no início do questionário, o formando foi solicitado a colaborar expressando suas expectativas profissionais e a visão da enfermagem sob a perspectiva dele, formando, que havia passado quatro anos no curso de graduação da EEUSP. Tratamento confidencial dos dados foi assegurado ao formandorespondente, enfatizando-se a sua participação de forma voluntária e anônima.

População -- os sujeitos do estudo foram os 63 alunos, matriculados, no $8^{\circ}$ e último semestre do curso de graduação da EEUSP. A listagem obtida na Seção de Graduação em agosto de 1999 relacionava 67 nomes, da qual foram excluídas a aluna que participava do presente estudo e mais três estudantes que cumpriam créditos-aula de dependência de disciplina em outros institutos da USP. 
Portanto a população deste estudo abrangeu 63 formandos, todos constantes da listagem oficial, dos quais 47 , isto é, $74,6 \%$, responderam ao questionário. Na listagem da Seção de Graduação com a relação de alunos formados no $2^{\circ}$ semestre de 1999 , constituindo a 53a. turma da EEUSP constavam 62 concluintes.

A listagem nominal dos estudantes foi usada apenas para controle da distribuição dos alunos entre as co-autoras e para controle das devoluções de questionários. Porém nenhuma marca ou sinal foi feito nos questionários que pudesse identificar os respondentes. Inicialmente o cronograma previa a coleta de dados em dois meses, setembro e outubro, porém três fatores dificultaram o cumprimento desse cronograma: a) os alunos estavam muito dispersos, distribuídos em diversos campos de estágio curricular, distantes uns dos outros, b) as alunas do $1^{\circ}$ ano estavam com um programa muito intenso de aulas teóricas, no campus da Universidade, reduzindo muito a disponibilidade de tempo; e, c) o não conhecimento visual dos colegas de séries mais adiantadas dificultava ainda mais a identificação e localização de respondentes potenciais para o preenchimento do questionário.

Essas dificuldades, ditas normais, para estudantes novatas na Escola, retardaram o cronograma, tornandose necessário prorrogar a coleta até o dia 9 de dezembro, data em que os formandos deveriam apresentar seus respectivos trabalhos de conclusão de curso em uma sessão pôster na sede da Escola.

A formanda, co-autora deste estudo, não participou na coleta de dados, pois sua amizade e proximidade com esses colegas poderiam exercer algum tipo de influência nas respostas, o que não era desejável. Mas, cooperou ativamente na identificação dos formandos e mesmo na localização deles quanto ao campo de estágio onde eles se encontravam. Assim, a abordagem de todos os formandos processou-se de maneira uniforme, pois nenhuma das alunas de $1^{\circ}$ ano conhecia anteriormente os formandos. Alguns deles preferiram levar o questionário para casa e devolvê-lo preenchido para uma das encarregadas de recolhê-lo. Os formandos que estavam em estágio em unidades de saúde não hospitalares foram os mais dificeis de serem localizados.

Alguns formandos não puderam ser abordados pessoalmente por encontrarem-se em aula, mas o docente ofereceu-se para fazer a entrega do questionário com a mensagem para sua devolução num local determinado. Nesses casos houve menor retorno de questionários, talvez por falta do contato direto do formando com a aluna que fazia a coleta.

Conforme explicado no início do questionário, as co-autoras, ao abordarem o formando, procuraram assegurar-lhe toda a liberdade possivel, não insistindo na devolução do questionário, em caso de resistência ou desinteresse.
Cada questionário preenchido recebeu um número aleatório no alto da página inicial e os dados, tratados confidencialmente, foram tabulados para análise em conjunto com todo o grupo de autores.

Considerando tratar-se de um grupo sem experiência prévia semelhante para abordarem pessoas desconhecidas, a tarefa tornou-se mais trabalhosa e complicada, porém todas elas destacaram o aprendizado auferido, o crescimento individual, a melhor compreensão da importância, da necessidade e das dificuldades que envolvem uma pesquisa. Sobretudo consideraram muito positiva a oportunidade de vencer a timidez e conhecer colegas veteranos e com eles conversar, e que sem essa coleta talvez nunca ocorresse tal aproximação.

As maiores dificuldades sentidas pelo grupo foram a dispersão dos formandos em locais e horários muito variados e a necessidade de buscar uma pessoa determinada a quem não conheciam anteriormente. Outras vezes, quando o formando estava identificado e localizado, ele não tinha disponibilidade para responder, seja porque estava tenso demais, encontrava-se em véspera de provas ou trabalhos de conclusão de curso. Mesmo nos dias de apresentação dos pôsteres, os formandos estavam tensos, seja pela presença do orientador e de outros docentes no ambiente, seja pela nova preocupação com o futuro emprego, preparação de curriculum vitae, onde começar a procurar trabalho, etc. Um aspecto considerado positivo foi a receptividade da maioria dos formandos que responderam ao questionário, e que procuraram ajudar mais, indicando onde e como encontrar outros colegas. Ainda, segundo a opinião das estudantes que fizeram a coleta, de um modo geral, os formandos abordados no início da pesquisa, isto é, setembro e outubro de 1999, preencheram os questionários de forma mais completa, respondendo a todos os itens, especialmente as perguntas abertas. Os questionários preenchidos depois desses meses o foram com mais pressa e, em geral, apenas as perguntas objetivas, sem deter-se nas questões abertas.

\section{APRESENTAÇÃO E ANÁLISE DOS RESULTADOS}

Do total de 63 estudantes matriculados no $8^{\circ}$ semestre do curso de graduação da EEUSP em agosto de 1999, 2 (3,2\%) eram do sexo masculino e $61(96,8 \%)$ do sexo feminino. Dessa população de matriculados, responderam ao questionário 46 estudantes do sexo feminino e $1(50,0 \%)$ do sexo masculino, e os respondentes atingiram o total de $74,6 \%$.

No grupo de formandos de 1999 a maioria absoluta estava entre os 21 e 25 anos de idade (85,1\%). 
Seis estudantes $(12,8 \%)$ estavam na faixa de 26 a 30 anos e apenas um aluno $(2,1 \%)$ com 36 anos e mais. Não havia aluno com idade entre 31 a 35 anos.

Em relação ao estado civil, o grupo dividia-se apenas em solteiros e casados, sendo $43(91,49 \%)$ solteiros e $4(8,51 \%)$ casados.

A pergunta sobre naturalidade do formando não foi utilizada porque $36 \%$ dos estudantes escreveram a palavra "brasileira", confundindo nacionalidade com naturalidade. Destes, a maioria procedia da Capital ou do Estado de São Paulo. De qualquer forma ela parece refletir uma realidade que transparece na pergunta subseqüente do questionário, referente ao local de residência atual, cujo resultado mostra que $41(87,2 \%)$ indicaram serem residentes na Capital, 3 $(6,9 \%)$ no interior do Estado de São Paulo e $3(6,9 \%)$ em outros locais. Questão similar no questionário era sobre o local onde pretendiam residir após a formatura. Mais uma vez a Capital de São Paulo foi a cidade eletiva com $52,1 \%$ das respostas e $39,6 \%$ dentro do interior do Estado. Dois estudantes iriam para outros locais, e houve um aluno que colocou duas alternativas de cidades, uma no interior do Estado e outra na capital de outro Estado. Houve uma resposta de aluno que informou não saber ainda onde iria residir e outro não respondeu à questão. É possivel que a existência de cursos e escolas de enfermagem nas várias cidades do interior e de outros estados, tenha diminuído a migração de estudantes em busca de escolas, e as da Capital sirvam primordialmente para atender à demanda local.

Dentre os respondentes, 24 (51,1\%) haviam prestado o exame vestibular para ingresso na EEUSP apenas uma vez, $12(25,5 \%)$ duas vezes e $9(19,1 \%)$ três vezes. Apenas um estudante $(2,1 \%)$ havia prestado quatro ou mais vezes e um não respondeu. Houve um total de 65 respostas, pois vários estudantes fizeram diferentes opções em cada exame vestibular que prestaram.

Dentre os 48 motivos da opção pela enfermagem, indicados pelos estudantes, 24 formandos $(50,0 \%)$ assinalaram que foi porque queriam uma profissão da saúde, mas estavam indecisos sobre a melhor escolha. Dentre eles 7 já haviam escolhido a enfermagem e 15 outras áreas de saúde. Nove formandos $(18,8 \%)$ citaram que a enfermagem era a carreira que pretendiam seguir de qualquer maneira. Cinco $(10,4 \%)$ indicaram ter escolhido a enfermagem porque era a opção que requeria menor pontuação, em comparação com as outras. Quatro formandos $(8,3 \%)$ optaram pela enfermagem por conhecerem uma enfermeira. Dois estudantes $(4,2 \%)$ mencionaram que o motivo era querer lidar com saúde, mas não ter logrado aprovação em medicina. Portanto, a maioria havia prestado exame vestibular apenas uma ou duas vezes. Um terço deles havia feito a opção pela enfermagem e 21,5\% pela medicina. Basicamente, parece que entre os respondentes, o desejo de seguir uma profissão da saúde ou a garantia de um "fértil mercado de trabalho" foram os motivos principais que os ajudaram na escolha, pois estavam incertos sobre a carreira a seguir, no momento de fazer a opção, como encontraram Angelo (7) e Spindola, Moreira(11).

Uma das questões do questionário era se a visão atual do formando sobre a profissão de enfermagem em relação ao tempo em que havia ingressado na EEUSP, havia mudado muito ou pouco, se havia mudado radicalmente ou se não havia mudado. Trinta estudantes $(63,8 \%)$ indicaram que havia mudado muito, $9(19,1 \%)$ que mudara pouco e $7(14,9 \%)$ que mudara radicalmente. Apenas um estudante $(2,1 \%)$ informou não haver mudado.

Alguns estágios no campo profissional, onde os alunos entram em contato direto com a realidade prática, podem lhes trazer decepções por não poderem realizar o que foi ensinado teoricamente. Lunardi (15), em seu estudo com enfermeiros, percebeu que o aumento do tempo de atuação na enfermagem compromete na motivação e entusiasmo do trabalhador, devido ao constante enfrentamento das dificuldades do cotidiano impostas pelas condições de trabalho assim como pela organização do trabalho.

Em seguida, os formandos foram solicitados a informar sobre o que pensavam a respeito da profissão de enfermagem antes de ingressar na EEUSP. A resposta hipotética, de que a profissão satisfazia ao anseio de ajudar os outros, obteve 15 respostas $(31,9 \%)$. Outra alternativa sugerida era de que a profissão de enfermagem era valorizada, alternativa assinalada por 8 estudantes $(17,9 \%)$. Sete estudantes $(14,9 \%)$ escreveram que era a profissão que trazia realização profissional e satisfazia ao desejo de trabalhar na área da saúde. As respostas, útil para si e para a família e profissão do futuro, foram escolhidas por 5 estudantes $(10,6 \%)$ cada uma. Dois estudantes $(4,3 \%)$ reconheciam tratar-se de uma profissão sacrificada, mesmo antes de ingressar no curso de enfermagem. Outras idéias mencionadas individualmente pelos estudantes foram: profissão fácil para entrar no mercado de trabalho; compensadora, mas desestimulante pela falta de reconhecimento; profissão que estuda a patologia e fisiologia humanas; enfermeiro é auxiliar de médico.

A questão subseqüente era como o formando percebia atualmente a profissão de enfermagem. Era uma questão aberta sem nenhum tipo de sugestão de resposta, para assegurar Liberdade de expressar as idéias, após ter passado pelos quatro anos de sua preparação acadêmica. Dezesseis formandos $(34,1 \%)$ percebiam a enfermagem como profissão do futuro, valorizada, reconhecida, importante, indispensável, útil, com oportunidade de ajudar os outros e em 
crescimento. Por outro lado, era vista como profissão pouco reconhecida, sacrificada, braçal, mecânica, com visão cientifica limitada e com um abismo entre a teoria e a prática, por 12 formandos $(25,5 \%)$. Sete respondentes $(14,9 \%)$ manifestaram que era profissão compensadora, mas não valorizada, e de que tinha mercado de trabalho, mas necessitava de mais dedicação e responsabilidade para o crescimento da classe. Apenas 4 estudantes $(8,5 \%)$ a viam negativamente, afirmando que os próprios profissionais não ajudavam. Poder-se-ia dizer que a maioria $(57,4 \%)$, mesmo fazendo algumas ressalvas, via a profissão positivamente, como compensadora, útil e que contava com mercado de trabalho favorável. Para justificar esse tipo de resposta, os respondentes alegaram que mais profissionais competentes seriam formados, que os enfermeiros estariam fazendo mais pesquisas, construindo uma nova imagem e ganhando mais espaço nas instituições. A Tabela 1 mostra o conjunto das idéias expressadas pelos respondentes.

Tabela 1- Distribuição de formandos segundo sua percepção atual sobre a profissão de enfermagem, 1999.

\begin{tabular}{|c|c|c|}
\hline Percepção dos formandos & $\begin{array}{l}\mathrm{n}^{\circ} \mathrm{de} \\
\text { formandos }\end{array}$ & \\
\hline Valorizada, reconhecida, importante, indispensável, do futuro, útil, com & 16 & 34,1 \\
\hline oportunidade de ajudar os outros, que está crescendo & & \\
\hline $\begin{array}{l}\text { Pouco reconhecida, sacrificada, braçal, mecânica, tem visão científica limitada, } \\
\text { abismo entre teoria e prática }\end{array}$ & 12 & 25,5 \\
\hline $\begin{array}{l}\text { Compensadora, mas não valorizada, necessita mais dedicação e } \\
\text { responsabilidade para o crescimento da classe }\end{array}$ & 7 & 14,9 \\
\hline $\begin{array}{l}\text { Tem mercado de trabalho, mas necessita de profissionais mais qualificados } \\
\text { para valorizar a classe e de mais autonomia }\end{array}$ & 4 & 8,5 \\
\hline Sofre preconceito, os próprios profissionais não ajudam & 3 & 6,4 \\
\hline Está sendo desvalorizada, outros profissionais ocupam seu espaço & 1 & 2,1 \\
\hline Não respondeu & 4 & 8,5 \\
\hline Total & 47 & 100,0 \\
\hline
\end{tabular}

De um modo geral, a grande maioria dos formandos, nos seus quatro anos que passaram na EEUSP, teve pouca participação nas atividades estudantis do Centro Acadêmico XXXI de Outubro (CA), pois segundo as respostas obtidas, 34 formandos $(68,0 \%)$ haviam sido membros do CA. Conforme o art. $3^{\circ}$ do Estatuto dessa agremiação, todo aluno de graduação da EEUSE é membro do CA (16). Apenas 9 alunos $(19,1 \%)$ haviam participado como membro na diretoria ou comissões agremiativas. Sobre a participação dos respondentes nos eventos promovidos pelo CA, 24\% das respostas foram em cursos, 16,9\% no Encontro Nacional de Estudantes de Enfermagem (ENEEn); e, 15,7\% em festas. Outros encontros nacionais ou regionais de estudantes de enfermagem também contaram com a adesão dos respondentes, mas em menor grau. Nove formandos $(19,1 \%)$ responderam não haver participado de evento algum do CA e outros nove não responderam. Houve mesmo uma resposta à essa pergunta com outra pergunta: que evento?, dando a entender que não teria tomado conhecimento de evento algum que tivesse sido realizado. Os que responderam à questão, registraram mais de um evento cada um.
Com respeito à participação discente em Departamentos e Colegiados da EEUSP, dentre os 47 respondentes, $17(36,2 \%)$ afirmaram nunca ter sido representante discente e $22(46,8 \%)$ deixaram a pergunta sem resposta. Dois alunos (4,3\%) participaram da Congregação, outros dois na Comissão da Biblioteca, e um aluno $(2,1 \%)$ representou os colegas em cada uma das Comissões de Cultura e Extensão Universitária (CCEx) e Graduação. Junto aos Departamentos da EEUSP, apenas dois, dos quatro existentes, contaram com um estudante desta turma, como representantes.

Sobre o sentimento dos formandos em relação ao curso de graduação que estavam em vias de completar, foi encontrado que a maioria realmente fez o que queria e pretendia exercer a profissão e outros, mesmo não tendo sido a opção inicial ou preferencial, acabaram gostando do curso e assim pretendiam permanecer na profissão, conforme mostra a Tabela 2. Um grupo de 31,9\% considerou que o curso the deu apenas a formação básica e que necessitaria de uma especialização para encontrar emprego melhor, mas não mencionaram abandono da profissão. Apenas um estudante afirmou que não era o que queria $e$ continuava não sendo. 
Tabela 2 - Distribuição de formandos segundo seu sentimento em relação ao curso de enfermagem na EEUSP, 1999.

\begin{tabular}{lcc}
\hline Sentimento dos formandos & $\begin{array}{c}\mathrm{n}^{\circ} \mathrm{de} \\
\text { formandos }\end{array}$ \\
\hline Era realmente o que queria fazer e pretende exercer a enfermagem logo que & 16 \\
possivel & 34,0 & 15 \\
Deu-lhe apenas o básico e crê necessitar de uma especialização para encontrar & 31,9 \\
emprego melhor & 8 \\
Não era o que queria, mas acabou gostando e agora quer exercer a profissão & 5 \\
Era o que queria, mas descobriu tarde demais o engano e vai exercer a profissão & 17,0 \\
enquanto busca algo melhor & 10,6 \\
Era o que queria, mas a profissão oferece poucas oportunidades de ascensão & 1 \\
salarial e há preconceito no âmbito institucional & 2,1 \\
Não era o que queria e continua não sendo & 1 \\
Era o que queria, mas pretende fazer outra faculdade. Não se arrependeu, & 1 \\
Acredita ter crescido, mas acha que precisa de mais autonomia & 2,1 \\
Total & 2,1 \\
\hline
\end{tabular}

As respostas à questão sobre o que o formando pretendia fazer, após sua formatura como enfermeiro, foram de que $22(45,8 \%)$ respondentes tinham a intenção de procurar imediatamente um emprego e começar a trabalhar e $14(29,2 \%)$ pretendiam fazer pós-graduação, tendo mesmo um deles escrito "já passei no mestrado", o que foi entendido como aprovado em exame de seleção para mestrado, e não que o tenha concluído. Cinco $(10,4 \%)$ pretendiam trabalhar e fazer especialização e $3(6,3 \%)$ pretendiam criar uma clínica particular em sociedade. Dois respondentes gostariam de trabalhar e cursar outra faculdade, e outros dois não pretendiam exercer a profissão, por enquanto.

Os formandos foram também solicitados a opinar, com base nas tendências atuais, se o reconhecimento e valorização do enfermeiro pela sociedade brasileira nos dez anos subseqüentes seria muito maior ou menor do que hoje, ou se estaria inalterado, justificando a resposta. A grande maioria (29) dos respondentes $(61,7 \%)$ opinou que seria muito maior e nenhum assinalou que seria menor. Quinze formandos consideraram que ficaria inalterado.

Entre as justificativa para sua escolha, foi encontrado que 6 desses respondentes consideraram que, de fato, seria muito maior do que hoje, porque nos próximos dez anos iriam formar-se mais profissionais competentes. Quatro respondentes acharam que enfermeiros estariam ganhando espaço nas instituições; dois opinaram que enfermeiros estariam fazendo mais pesquisas e construindo uma nova imagem; e outros dois referiram que a sociedade reconheceria a profissão de enfermagem como essencial dentro do hospital.

Outras justificativas mencionadas espontaneamente pelos formandos, em menor porcentagem foram: dependeria de mobilização da classe e a valorização ocorreria quando o curso fosse mais valorizado pelos docentes $e$ houvesse novas regulamentações sobre o ensino; dependeria do sistema de saúde e de órgãos representativos da enfermagem; se existissem somente técnicos e enfermeiros haveria melhor assistência aos pacientes.

Entre os respondentes que assinalaram que a questão do reconhecimento e valorização pela sociedade estaria inalterada, dois formandos alegaram que falta união profissional e engajamento por melhores condições de trabalho (2 respostas). Outros formandos emitiram diferentes motivos para que a situação continue inalterada: enquanto enfermeiros não se conscientizarem do quanto precisam estudar; só melhorará se começar a haver mudança desde o vestibular, melhor seleção e preparação; dez anos é pouco para que haja reconhecimento da profissão; profissionais de enfermagem são acomodados, não lutam para demonstrar o valor que têm; as pessoas desconhecem a importância da profissão e sempre a associam a fetiches; a midia mantém uma característica não fidedigna da enfermagem e a população não sabe diferenciar auxiliares, técnicos e enfermeiros.

Os formandos, colocando-se em uma posição otimista, foram solicitados a descrever quais os grandes progressos que a profissão de enfermagem conheceria no prazo de 20 ou 30 anos. Oito respondentes $(18,6 \%)$ afirmaram que os enfermeiros teriam maior autonomia e mais reconhecimento; seis $(14,0 \%)$ que haveria mais pesquisas e que elas seriam aplicadas no campo prático e $4(9,3 \%)$ que o profissional seria mais competente e especializado e atuaria mais em prevenção. Outras justificativas encontradas foram: o grande progresso será a melhor seleção dos alunos e melhoria do ensino; o enfermeiro cuidará realmente do paciente; haverá maior número de consultas de enfermagem, enfermeiros domiciliares (home care) e casas de parto; haverá um pensar mais positivo do que de hoje, que se não for barrado, levará 
à evolução da profissão; maior clareza quanto à identidade profissional e diferenciação com auxiliares e técnicos; ampliação do mercado e valorização da profissão; será tão requisitada quanto a medicina; haverá unificação das várias categorias da enfermagem; deixará de ser submissa e aprimorar-seá mais. Dois estudantes declararam-se otimistas sem especificar o progresso.

Quatro formandos responderam a essa pergunta, em caráter pessoal, ou seja, escreveram que estariam gerenciando ou estariam ocupando um bom cargo em hospital, ou estariam fazendo mestrado ou doutorado. Um respondente escreveu que não acredita que haverá grandes progressos. Quatro formandos não responderam e um informou nada pensar sobre o assunto.

Em seguida, os formandos, em nova questão aberta e colocando-se desta vez, em uma posição realista, deveriam descrever como o enfermeiro seria visto pela sociedade dentro de 20 ou 30 anos. Vinte formandos $(42,6 \%)$ afirmaram que o enfermeiro estaria mais bem posicionado, valorizado, reconhecido, com mais autonomia dentro da equipe multiprofissional. Quatro estudantes $(8,5 \%)$ escreveram que o enfermeiro estaria sendo visto como qualquer profissional de nivel superior. Outras respostas encontradas foram: profissão não submissa à medicina; predominantemente administrativa; importante na prevenção de doenças, que realiza diagnósticos e trata; simplesmente como enfermeiro que ainda luta por um "lugar ao sol"; profissão da área da saúde sem papel definido. Outros consideraram-se realistas sem especificação alguma; ou que poderia ser visto como ajudante de médico ou serviçal que dá banho. Onze formandos $(23,4 \%)$ deixaram de preencher essa pergunta.

Cabe lembrar que, segundo Lunardi(7), "a formação disciplinar dos enfermeiros está vinculada a amplos processos históricos, sociais, econômicos, culturais e científicos. A questão do gênero na enfermagem também precisa ser considerada, pois diante da elevada porcentagem de profissionais do sexo feminino que a exercem, o fazer e o cuidar, ensinado aos estudantes de enfermagem traz muito ainda das características do fazer doméstico, do fazer entendido como o fazer da mulher, um trabalho tido como invisivel, sem começo nem fim, não pago e pouco valorizado, muitas vezes percebido apenas quando não realizado". Muitos profissionais que atuam nos campos de estágio dos alunos, podem ser oriundos de escolas que tinham, ou ainda têm, resquícios desse tipo de formação, o que pode ter influenciado na visão negativa dos alunos, gerando algumas respostas como as acima referidas.

Portanto, dentro de uma percepção otimista, os formandos incluíram entre os grandes progressos da enfermagem .nos próximos 20 ou 30 anos, a maior autonomia no exercício profissional pelos enfermeiros, maior reconhecimento da sociedade, mais pesquisas e maior competência técnica. Já na ótica realista, quando se esperava que os respondentes seriam mais cautelosos com relação às décadas futuras, 42,6\% afirmaram que o enfermeiro estaria melhor posicionado, valorizado, reconhecido e mais autônomo.

Os formandos foram convidados a manifestar seu sentimento com relação ao "ser enfermeiro", podendo assinalar uma das seis hipóteses listadas ou escrever outra, se entre as listadas não houvesse uma que se aproximasse de seu sentimento. Vinte e um respondentes $(44,7 \%)$ assinalaram que "ser enfermeiro" era o primeiro degrau de uma carreira que pretendiam percorrer; 12 (25,5\%) concordaram que "ser enfermeiro" concretizaria seu sonho de ter uma profissão e ser útil à sociedade; 6 (12,8\%) consideram ser motivo de orgulho e satisfação para si e para a família. Outras alternativas encontradas em menor proporção foram: profissão que tem mercado de trabalho fácil; etapa necessária antes de fazer pósgraduação; forma de ganhar a vida honestamente; entrar para a profissão e manter-se, mas desistirá se não houver melhora; apenas uma fase da vida que não será permanente.

A última pergunta do questionário era sobre a intenção dos formandos em relação à classe dos enfermeiros, especialmente seu engajamento com entidades de classe, como a Associação Brasileira de Enfermagem (ABEn) e outras mencionadas no texto. Vinte e oito $(33,3 \%)$ dos respondentes assinalaram a resposta fazer pesquisas e escrever trabalhos para apresentar em eventos científicos e 25 (29,8\%) pretendiam participar de eventos técnicos ou científicos das sociedades de especialistas. Treze formandos $(15,5 \%)$ gostariam de colaborar em comissões e grupos de trabalho para estudos sobre enfermagem e 10 (11,9\%) de associar-se à ABEn como membro efetivo, logo após a formatura. Atuar ativamente nas entidades de classe e não continuar na profissão foram citadas por três formandos para cada resposta. Um formando disse que pretendia seguir carreira docente e outro afirmou não saber ainda o que iria fazer. Como se tratava de questão que permitia assinalar mais de uma resposta, vários respondentes assim procederam. Um formando indagou: o fato de associar-se ou oeupar cargos na ABEn ou Sindicato de Enfermeiros leva a nossa classe a algum lugar?

A formação profissional para ser completa deveria incluir a participação do estudante em atividades sociais, agremiativas e comunitárias. Para tanto, um bom início poderia ser a participação no Centro Acadêmico (CA) e posteriormente em entidades de classe, como a ABEn e sociedades de especialistas. Entretanto, dentro dessa turma de formandos, poucos foram os que efetivamente participaram de atividades 
agremiativas ou associativas, na ABEn, por exemplo que incentiva a participação de alunos, especialmente nos últimos semestres. Embora possa existir problema econômico para alguns alunos quanto ao pagamento de anuidade, deve haver também falta de conhecimento e mais ainda de incentivo por parte dos próprios profissionais, docentes ou não. Embora o docente não deva ser a "única fonte de influência, deve ser uma fonte positiva(5)". Essa autora encontrou insegurança por falta de maturidade, medo de se expressar e receber represálias, intervenções inócuas nas sugestões de mudanças; e até comodismo gerando imobilismo, nos depoimentos dos alunos. Individualmente docentes poderiam estimular e facilitar maior participação de alunos, especialmente em eventos técnicos e científicos promovidos pela ABEn, EEUSP e outras entidades. Dentro do âmbito da EEUSP, é preocupante a pouca participação de alunos como representante discente em seus colegiados e departamentos. Embora seja o canal mais apropriado para levar aos docentes e autoridades universitárias o ponto de vista discente e os problemas existentes no curso e nos programas curriculares, vem sendo pouco utilizado pelos alunos, seja pela dificuldade em conciliar horários de .reuniões com os estágios e aulas, dificuldade de entender a dimensão dos assuntos tratados ou a dinâmica dessas reuniões ou até mesmo falta de motivação ou interesse.

Apesar das reiteradas manifestações sobre a necessidade de união profissional, engajamento na luta por melhores condições de trabalho, pela valorização da classe e melhor conscientização dos enfermeiros, quando se lhes foi dada a oportunidade de expressar sobre sua futura intenção de uma possivel participação em entidades de classe, apenas $11,9 \%$ dos formandos mencionaram sua intenção de associar-se à ABEn e $15,5 \%$ de trabalhar em comissões ou grupos de trabalho para estudos sobre enfermagem.

Esse tipo de resposta pode refletir a pouca ênfase ainda dada pelos docentes-enfermeiros, seja em aulas ou estágios, seja em outras formas de participação em atividades da categoria profissional, tais como o exercício de cargos diretivos e de liderança nacional em entidades de classe da enfermagem e não apenas em eventos científicos. É inegável que pesquisas de enfermagem contribuem para o desenvolvimento da profissão e a apresentação de trabalhos científicos são necessários para divulgação dos achados e sua implementação na prática. Mas, paralelamente a essas atividades, enfermeiros docentes devem assumir muito mais o seu compromisso e responsabilidade com os destinos da profissão. Para tanto, estudantes de enfermagem desde o início de seus cursos precisam ser motivados e incentivados a participarem também de atividades agremiativas no $\mathrm{CA}$, como representante discente em colegiados e departamentos e depois em atividades associativas que possam beneficiar a coletividade, no exercício mesmo da cidadania. A existência de muito mais modelos de enfermeiros verdadeiramente dedicados à profissão e ao desenvolvimento da classe poderia influir efetivamente no interesse e entusiasmo dos estudantes para a continuidade dessa tarefa de tornar a Enfermagem uma profissão cada vez mais visivel e valorizada na sociedade.

\section{CONCLUSÕES}

Os resultados levantados permitem concluir que os sentimentos da maioria dos alunos em relação ao curso de graduação de enfermagem da EEUSP são de satisfação por haver concluído essa etapa e pretendem exercer a profissão. Mesmo aqueles que não tiveram a Enfermagem como opção inicial ou preferencial, acabaram gostando do curso e, assim, pretendem permanecer na profissão.

Após quatro anos de sua preparação acadêmica no curso de graduação da EEUSP, pode-se afirmar que a maioria $(57,4 \%)$ via a profissão de maneira positiva, como profissão do futuro, valorizada, reconhecida, importante, indispensável, compensadora, útil, e que contava com mercado de trabalho favorável, mesmo que com algumas ressalvas. Havia 25,5\% de formandos que ainda a percebiam como profissão pouco reconhecida, sacrificada, braçal, mecânica, com visão cientifica limitada e com um abismo entre a teoria e a prática. Fato auspicioso foi a resposta de quase dois terços dos respondentes de que, mantidas as tendências atuais, o reconhecimento e valorização do enfermeiro pela sociedade brasileira nas próximas décadas seria muito maior.

Com relação às hipóteses enunciadas, confirmase a primeira quanto ao curso de graduação pois segundo os dados colhidos, modificou-se a percepção do estudante quanto à profissão. A segunda hipótese não se confirma de todo, mas a maioria é otimista, entusiasmada e orgulhosa da profissão abraçada e demonstra visão positiva da enfermagem, embora, uma parcela da população apresentasse cautela e preocupação com a; situação. Quanto ao desejo de ajudar o próximo, sempre manifestado no inicio do curso, e considerada na terceira hipótese, pode-se verificar que ao concluir o curso de graduação, o formando de enfermagem torna-se mais realista, pois percebe que pode ajudar os outros sim, como parte de seu trabalho profissional, unindo o idealismo inicial ao realismo cotidiano.

\section{RECOMENDAÇÕES}

Vivenciando e sentindo os problemas no dia-adia das aulas e estágios no Curso Graduação de Enfermagem, as autoras discentes, à guisa de 
recomendação aos docentes e autoridades da USE, propuseram o seguinte:

- contratação de docentes que tenham exercido a profissão como enfermeiros, antes de se tornarem pesquisadores e professores, e que estes demonstrem capacidade de comunicação com alunos;

- melhor distribuição de recursos materiais, pois encontraram contrastes dentro da mesma Universidade, com unidades muito carentes (laboratório de enfermagem, por exemplo) e outras muito aquinhoadas;

- diminuição de alunos ingressantes no curso de graduação a fim de melhorar o aproveitamento, pois consideram altamente frustrante o sistema de sorteio ou média ponderada, para seleção de alunos interessados em uma disciplina optativa complementar para cumprir o estágio curricular, que é obrigatório, num campo ou área departamental que não era de seu interesse;

- maior envolvimento de docentes enfermeiros em atividades de liderança nacional da classe de enfermagem, que serviriam como modelos para os alunos. Ao mesmo tempo, os professores deveriam estimular os alunos, inclusive com facilidade de horários para que eles possam participar de atividades agremiativas, que serão futuramente as atividades que irão desempenhar nas organizações da classe e assumir mesmo posições de liderança nacional.

\section{REFERÊNCIAS BIBLIOGRÁFICAS}

(1) Oguisso T, Gaspar JC, Kajimoto DS, Yamamoto W. Ano 2030 - a aurora da profissão do milênio: Enfermagem - uma visão prospectiva de estudantes de graduação de enfermagem. Rev Esc Enferm USP 1999; 33(4): 384-90.

(2) Arcuri EM, Araujo TL, Oliveira MAC. Fatores que influenciaram alunos ingressantes na Es cola de Enfermagem da USP, em 1981, na escolha da enfermagem como opção profissional. Rev Esc Enferm USP 1983; 17(1):519,

(3) Horta ALM, Bonilha ALL, Ribeiro MO. Características e aspirações do atual graduando de enfermagem comparação entre duas instituições de ensino. Rev Esc Enferm USP 1988; 22(3):323-337,

(4) Vargens OMC. O homem enfermeiro e sua opção pela enfermagem. [dissertação] São Paulo (SP): Escola de Enfermagem da USP; 1989.

(5) Nakamae DD. Formação de atitudes ético-profissionais: pensamentos e experiências de estudantes de enfermagem, [livre-docência] São Paulo (SP): Escola de Enfermagem da USP; 1992
(6) Jorge MSB. O aluno ingressante na universidade - uma perspectiva de compreensão. [dissertação] Ribeirão Preto (SP): Escola de Enfermagem de Ribeirão Preto - USP; 1992.

(7) Angelo M. A opção pela enfermagem. Rev Esc Enferm USP 1995; 29(1):3-7.

(8) Barbosa MLD. Estudo da percepção do aluno da Escola de Enfermagem da Universidade Federal de Minas Gerais sobre o processo de sua formação acadêmica. [dissertação] Belo Horizonte (MG): Universidade Federal de Minas Gerais; 1996.

(9) Padilha MICS, Nazario NO, Moreira MC. A compreensão do ideário da enfermagem para a transformação da prática profissional. Rev Bras Enferm 1997; 50(3):307-22.

(10) Manninen E, Changes in nursing students' perceptions of nursing as they progress through their education. J Adv Nur 1998; 27(2): 390-8.

(11) )SpindolaT, Moreira A. O aluno e a enfermagem: por que esta opção profissional? Esc Anna Nery Rev Enferm 1999; 3(2): 25-36.

(12) )Silva MTN. Sobre enfermagem-enfermeira: o imaginário dos familiares das alunas ingressantes no curso de graduação. [dissertação] Rio de Janeiro (RJ): Escola Enfermagem Anna Nery da UFRJ; 2000.

(13) Freitas KSS. O cuidado no processo de ser e viver de educandas de enfermagem. [dissertação] Florianópolis (SC): UFSC/FURG/UFPel/URCAMP; 2000.

(14) Kerlinger F. Metodologia da pesquisa em ciências sociais: um tratamento conceituai. São Paulo: EPU/EDUSP; 1994.

(15) Lunardi WD. Prazer e sofrimento no trabalho: contribuições à organização do processo de trabalho da enfermagem. [dissertação] Porto Alegre (RS): Faculdade de Ciências Econômicas da UFRG; 1995.

(16) Centro Acadêmico XXXI de Outubro. Estatutos. São Paulo; Sem data,(mimeografado).

(17) Lunardi VL. Fios visiveis/invisiveis no processo educativo de (des)construção do sujeito enfermeira. [dissertação] Porto Alegre (RS): Escola de Enfermagem da UFRS; 1994.

\section{Artigo recebido em 18/04/00}

Artigo aprovado em 19/12/01 